\title{
Model Predictive Control of Automotive Powertrains - First Experimental Results
}

\author{
Bart Saerens, Moritz Diehl, Jan Swevers and Eric Van den Bulck
}

\begin{abstract}
This paper illustrates the capabilities of model predictive control for the control of automotive powertrains. We consider the minimization of the fuel consumption of a gasoline engine through dynamic optimization. The minimization uses a mean value model of the powertrain and vehicle. This model has two state variables: the pressure in the engine manifold and the engine speed. The control input is the throttle valve angle. The model is identified on a universal dynamometer. Optimal state and control trajectories are calculated using Bock's direct multiple shooting method implemented in the software MUSCOD-II. The developed approach is illustrated both in simulation and experimentally for a test case where a vehicle accelerates from $1100 \mathbf{r p m}$ to $3700 \mathbf{r p m}$ in $30 \mathbf{s}$. The optimized trajectories yield minimal fuel consumption. The experiments show that the optimal engine speed trajectory yields a reduction of the fuel consumption of $12 \%$ when compared to a linear trajectory. Thus, it is shown that, even with a simple model, a significant amount of fuel can be saved without loss of the fun-to-drive.
\end{abstract}

\section{INTRODUCTION}

Triggered by rising fuel prices, stringent legal norms and increasing environmental awareness of the customer, car manufacturers are producing vehicles with high fuel efficiency and low emissions. This is possible due to new components and technologies that are introduced in automotive powertrains (e.g. turbo charging, exhaust gas recirculation, continuous variable transmission, hybrid powertrain, electronic throttle control). Unfortunately, it seems that the control software of powertrains remains backward with respect to their complexity. While mostly strategies that are based on heuristics and look-up tables are implemented, it was shown that model predictive control has a large potential for control of automotive powertrains [1]-[4]. This is supported by the fast proliferation of powerful embedded components that allow complex real-time control.

Speed transients (accelerations and decelerations) frequently occur in city traffic and significantly increase the fuel consumption. Smoothing these transients by a look-ahead capability can improve the fuel economy [5]. Unfortunately, constrained by the surrounding traffic, this method is not

Research funded by a Ph.D grant of the Institute for the Promotion of Innovation through Science and Technology in Flanders (IWT-Vlaanderen).

This work also benefits from K.U.Leuven-BOF EF/05/006 Center-ofExcellence Optimization in Engineering and the Belgian Programme on Interuniversity Attraction Poles, initiated by the Belgian Federal Science Policy Office (DYSCO)

B. Saerens, J. Swevers and E. Van den Bulck are with the department of mechanical engineering, K.U.Leuven, Celestijnenlaan 300, B-3001 Heverlee, Belgium bart. saerens@mech.kuleuven. be

M. Diehl is with the electrical engineering department and the optimization in engineering center (OPTEC), K.U.Leuven, Kasteelpark Arenberg 10, B-3001 Heverlee, Belgium.

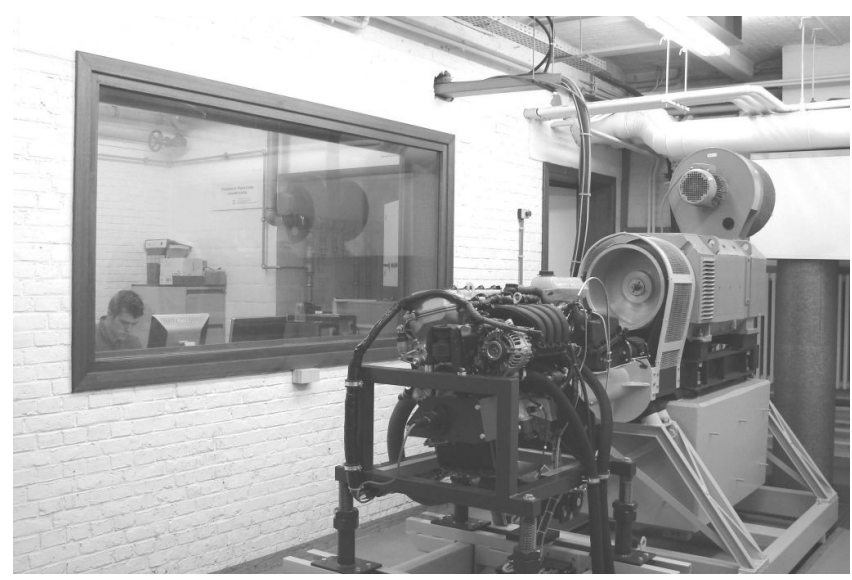

Fig. 1. Universal dynamometer with a Toyota 1.61 3ZZ-FE gasoline engine of K.U. Leuven, on which the experiments in Section IV-B were conducted. Significant fuel savings were possible using optimization based control.

always applicable and jeopardizes the driveability and funto-drive. A better strategy optimizes the speed trajectory to minimize fuel consumption [6], resulting in fuel-optimal trajectories as often used in aerospace applications.

The purpose of this paper is to present the first results of a research project on powertrain control with nonlinear model predictive control. These results concern optimal throttle valve control in speed transients and show the capability of this control method for fuel consumption minimization. In contrast to most published papers on predictive powertrain control, this paper optimizes trajectories instead of tracking given setpoints. Thus, the control method can be referred to as optimizing model predictive control.

Section II gives a short introduction to model predictive control. Section III describes the dynamic model of the powertrain and vehicle. Section IV gives results for a specific optimization problem, both in numerical simulation and in experiments on a dynamometer, see Fig. 1. Section V concludes this paper and takes a look at future work.

\section{MODEL PREDICTIVE CONTROL}

In model predictive control (MPC) [7], a cost function is minimized at each sampling time to obtain optimal control inputs for a system. This allows for an open-loop control approach to generate a feedback control. The open-loop control is calculated with dynamic optimization, which uses dynamic system models to minimize an objective function with multiple constraints taken into account. 


\section{A. Dynamic optimization}

Dynamic optimization [8] can solve an optimal control problem of the following simplified form:

$$
\begin{aligned}
\min _{x(.), u(.)} E(x(T))+\int_{0}^{T} L(x(t), u(t)) d t, & \\
\text { subject to } & \\
\dot{x}(t)-f(x(t), u(t)) & =0, \quad t \in[0, T], \\
h(x(t), u(t)) & \geq 0, \quad t \in[0, T], \\
r_{\mathrm{s}}(x(0)) & =0, \\
r_{\mathrm{e}}(x(T)) & =0 . \\
&
\end{aligned}
$$

The optimization determines the optimal control input $u(t)$ and corresponding state variables $x(t)$ for the interval $[0, T]$ that minimize the objective function (1a). The model differential equations are denoted by equation (1b). Equation (1c) is a general nonlinear inequality constraint and equations (1d), (1e) describe start and end point constraints. There are several approaches to solve an optimal control problem of the form (1) [9]. Bock's direct multiple shooting method [10] is used in this paper, because it is typically easy to use in practical applications and because of its favorable treatment of terminal constraints. The software MUSCOD-II [11] is used.

\section{B. Feedback control}

Model predictive control solves in each discrete-time step an optimal control problem of the form (1) over a control horizon $T$. Only the first fraction of the optimal control inputs $u^{*}$ is applied to the system, until in a new iteration, new optimal control inputs are calculated. This way, a feedback control is obtained by repeatedly solving an open-loop optimal control problem. This feedback control can handle unforeseen disturbances and deal with modelplant-mismatch. If necessary, the optimal control problem formulation can be adjusted in every iteration. This is an advantage in automotive applications, where constraints or the objective function can change while driving, due to a changing traffic situation or behavior of the driver.

\section{Optimal throttle valve control for a vehicle acceleration}

Let's take a look at a specific optimal control problem: optimal throttle valve control during a vehicle acceleration. The aim is to accelerate a vehicle in a given time using the least possible amount of fuel. The speed trajectory is optimized. For simplicity, the gear is fixed. We assume a dynamic model with state variables $x=\left(n, p_{\mathrm{m}}\right)$ (with $n$ the engine speed and $p_{\mathrm{m}}$ the intake manifold pressure) and a control input $u$, being the throttle. The following equations
TABLE I

SPECIFICATIONS OF THE TOYOTA 3ZZ-FE GASOLINE ENGINE

\begin{tabular}{cc}
\hline no. of cylinders and arrangement \\
valve mechanism & 4 in-line \\
displacement & 16-valve DOHC, chain drive \\
bore x stroke & $1598 \mathrm{~cm}^{3}$ \\
compression ratio & $79.0 \mathrm{~mm} \times 81.5 \mathrm{~mm}$ \\
max. power & 10.5 \\
max. torque & $81 \mathrm{~kW} \mathrm{@6000} \mathrm{rpm}$ \\
\hline
\end{tabular}

give the optimization problem in the standard form (1):

$$
\begin{aligned}
\min _{x(.), u(.)} \int_{0}^{T} \dot{m}_{\mathrm{f}}(x(t)) d t, & \\
\text { subject to } & \\
n(0)-n_{\mathrm{s}} & =0, \\
\dot{n}(0) & =0, \\
n(T)-n_{\mathrm{e}} & =0, \\
\dot{n}(T) & =0, \\
n(t)-n_{\mathrm{s}} & \geq 0, \quad t \in[0, T], \\
1 \geq u(t) & \geq 0, \quad t \in[0, T], \\
\dot{x}(t)-f(x(t), u(t)) & =0, \quad t \in[0, T] .
\end{aligned}
$$

Equation (2a) formulates that the state variables $x(t)$ and the corresponding control input $u(t)$ for $t \in[0, T]$ should be chosen in order to minimize the integral of the fuel flow rate $\dot{m}_{\mathrm{f}}$. Equations (2b)-(2e) specify start and end constraints. Equations (2f), (2g) bound the state variables and control input. Equation (2h) represents the system model as given in the next section.

\section{POWERTRAIN AND VEHICLE MODEL}

This section gives a brief overview of the dynamic model of the powertrain and the vehicle of a Toyota Corolla Verso. A complete description of the model is given in [12]. The powertrain consists of a gasoline engine, transmission and driveline. Since this paper focuses on the fuel consumption during speed transients, there is no need to model dynamics that are much faster than the longitudinal dynamics of the vehicle.

\section{A. Gasoline engine model}

The engine model is a mean value phenomenological model. The considered engine is a Toyota 1.61 3ZZ-FE gasoline engine, which is mounted on a fully equipped universal dynamometer. Possible measurements on the dynamometer are engine speed, effective engine torque, intake air flow mass, intake manifold pressure and temperature, engine temperature, fuel consumption and ratio of equivalence. The throttle valve of the engine can be controlled. Certain model parameters are determined from a set of steady-state experiments at various engine speeds and throttle valve positions. Table I gives the specifications of the gasoline engine.

The engine model has three subsystems: the air intake, the fuel delivery and the torque production. Since this paper 
focusses only on fuel consumption, the exhaust system is not modeled.

The air intake is controlled with the throttle valve. The ideal gas law and conservation of mass yield the evolution equation of the pressure $p_{\mathrm{m}}[\mathrm{Pa}]$ inside the intake manifold:

$$
\dot{p}_{\mathrm{m}}=\frac{r T_{\mathrm{m}}}{V_{\mathrm{m}}} \frac{p_{\mathrm{a}}}{\sqrt{r T_{\mathrm{a}}}} A(\alpha) C_{\mathrm{d}} f_{\mathrm{n}}\left(\frac{p_{\mathrm{m}}}{p_{\mathrm{a}}}\right)-\frac{\eta_{\mathrm{v}} V_{\mathrm{tot}}}{2 V_{\mathrm{m}}} n p_{\mathrm{m}}
$$

where $r[\mathrm{~J} /(\mathrm{kgK})]$ is the specific gas constant of air, $T_{\mathrm{m}}$ $[\mathrm{K}]$ and $V_{\mathrm{m}}\left[\mathrm{m}^{3}\right]$ the temperature inside and the volume of the manifold, $p_{\mathrm{a}}[\mathrm{Pa}]$ and $T_{\mathrm{a}}[\mathrm{K}]$ the ambient pressure and temperature, $A(\alpha)\left[\mathrm{m}^{2}\right]$ the frontal flow area of the throttle body, $\alpha$ [rad] the throttle valve angle, $C_{\mathrm{d}}[-]$ the throttle body discharge coefficient and $f_{\mathrm{n}}[-]$ a function that takes into account possible sonic choking of the air flow through the throttle body. $\eta_{\mathrm{v}}[-]$ is the volumetric efficiency, $V_{\text {tot }}\left[\mathrm{m}^{3}\right]$ the total cylinder volume and $n[\mathrm{rad} / \mathrm{s}]$ the engine speed. $C_{\mathrm{d}}$ and $\eta_{\mathrm{v}}$ are determined experimentally on the dynamometer, $C_{\mathrm{d}}$ as a function of $\alpha$ and $p_{\mathrm{m}}$, and $\eta_{\mathrm{v}}$ as a function of $n$ and $p_{\mathrm{m}}$.

The amount of injected fuel is normalized by the ratio of equivalence $\phi[-]$ :

$$
\phi=\frac{\mathrm{AFR}}{\mathrm{AFR}_{\mathrm{st}}},
$$

where AFR is the real air-fuel ratio and $\mathrm{AFR}_{\mathrm{st}}$ the stoichiometric air-fuel ratio. $\phi$ is determined by the engine control unit (ECU). $\phi$ and the fuel mass flow rate $\dot{m}_{\mathrm{f}}[\mathrm{kg} / \mathrm{s}]$ into the cylinder are determined experimentally as a function of $p_{\mathrm{m}}$ and $n$. The fast fuel dynamics are neglected in the model.

The combustion and torque production are modeled with the effective efficiency $\eta_{\mathrm{e}}[-]$ :

$$
T_{\mathrm{e}}=\eta_{\mathrm{e}} \frac{\dot{m}_{\mathrm{f}} Q_{\mathrm{v}}}{2 \pi n}
$$

where $T_{\mathrm{e}}[\mathrm{Nm}]$ is the effective engine torque (the torque measured on the engine shaft), $Q_{\mathrm{v}}[\mathrm{J} / \mathrm{kg}]$ the heating value of gasoline and $\eta_{\mathrm{e}}$ is determined with experimental tests as a function of $p_{\mathrm{m}}$ and $n$.

\section{B. Transmission and driveline model}

The transmission and driveline convert the force $F_{\mathrm{V}}[\mathrm{N}]$ on the wheels of the vehicle into a load torque $T_{1}[\mathrm{Nm}]$ on the engine shaft. This is modeled by means of algebraic relations:

$$
F_{\mathrm{v}} v_{\mathrm{v}}=2 \pi n T_{1} \eta_{\mathrm{m}}
$$

where $v_{\mathrm{v}}[\mathrm{m} / \mathrm{s}]$ is the vehicle velocity and $\eta_{\mathrm{m}}[-]$ the power transmission efficiency which is considered constant. Further:

$$
v_{\mathrm{v}}=R_{\mathrm{w}} \frac{2 \pi n}{i_{\mathrm{D}} i_{\mathrm{G}}}
$$

where $R_{\mathrm{W}}[\mathrm{m}]$ is the radius of the wheels, $i_{\mathrm{D}}[-]$ the reduction ratio of the differential and $i_{\mathrm{G}}[-]$ the reduction ratio of the gearbox.
TABLE II

PARAMETERS OF THE POWERTRAIN AND VEHICLE MODEL

\begin{tabular}{cc}
\hline$A(\alpha)=0.00158-0.001595 \cos (\alpha) \mathrm{m}^{2}$ & $r=287 \underset{\mathrm{kgK}}{\mathrm{J}}$ \\
$\mathrm{AFR}_{\mathrm{st}}=14.7$ & $S C_{\mathrm{x}}=1 \mathrm{~m}^{2}$ \\
$f_{\mathrm{r} 0}=0.015$ & $T_{\mathrm{a}}=293 \mathrm{~K}$ \\
$g=9.81 \frac{\mathrm{m}}{\mathrm{s}^{2}}$ & $V_{\mathrm{m}}=2.04 .10^{-3} \mathrm{~m}^{3}$ \\
$i_{\mathrm{D}}=4.31$ & $V_{\mathrm{tot}}=1.598 .10^{-3} \mathrm{~m}^{3}$ \\
$i_{\mathrm{G}}=3.32 / 2.00 / 1.36 / 1.01 / 0.82$ & $Q_{\mathrm{v}}=43700 \frac{\mathrm{kJ}}{\mathrm{kg}}$ \\
$I_{\mathrm{m}}=1.0256 \mathrm{kgm}^{2}$ & $R_{\mathrm{W}}=0.316 \mathrm{~m}$ \\
$k=0.002 \frac{\mathrm{s}^{2}}{\mathrm{~m}^{2}}$ & $\eta_{\mathrm{m}}=1$ \\
$M_{\mathrm{v}}=1365 \mathrm{~kg}$ & $\kappa=1.4$ \\
$p_{\mathrm{a}}=101325 \mathrm{~Pa}$ & $\rho_{\mathrm{a}}=1.2 \frac{\mathrm{kg}}{\mathrm{m}^{3}}$ \\
$p_{\mathrm{r}, \mathrm{crit}}=0.528$ & $\theta=0 \mathrm{rad}$ \\
\hline
\end{tabular}

\section{Vehicle model}

The vehicle model represents the longitudinal dynamics of the vehicle:

$$
F_{\mathrm{v}}=\underbrace{M_{\mathrm{v}} \frac{d v_{\mathrm{v}}}{d t}}_{\text {inertia }}+\underbrace{S C_{\mathrm{x}} \frac{\rho_{\mathrm{a}} v_{\mathrm{v}}^{2}}{2}}_{\text {wind resistance }}+\underbrace{f_{\mathrm{r}} M_{\mathrm{v}} g \cos \theta}_{\text {rolling resistance }}+\underbrace{M_{\mathrm{v}} g \sin \theta}_{\text {road slope }},
$$

where $M_{\mathrm{v}}[\mathrm{kg}]$ is the mass of the vehicle, $S\left[\mathrm{~m}^{2}\right]$ the frontal surface of the vehicle, $C_{\mathrm{X}}$ [-] the drag coefficient of the vehicle, $\rho_{\mathrm{a}}\left[\mathrm{kg} / \mathrm{m}^{3}\right]$ the density of air, $f_{\mathrm{r}}=f_{\mathrm{r} 0}\left(1+k v_{\mathrm{v}}^{2}\right)[-]$ the friction coefficient and $\theta[\mathrm{rad}]$ the slope of the road.

Model parameters for the drivetrain and vehicle model are based on a Toyota Corolla Verso [13]. Values for these parameters are shown in Table II.

\section{Linking of the models}

The link between the engine model and the models of the transmission, driveline and vehicle is given by:

$$
I_{\mathrm{m}} \frac{d n}{d t}=T_{\mathrm{e}}-T_{1}
$$

where $I_{\mathrm{m}}\left[\mathrm{kgm}^{2}\right]$ is the moment of inertia of the powertrain.

To summarize, equations (3)-(9) represent the system as a nonlinear state space model $(2 \mathrm{~h})$. The normalized throttle valve angle $u$ is the control input, with $u$ a linear scaling of the throttle valve angle $\alpha$ : $u=\frac{2 \alpha}{\pi}$, thus $0 \leq u \leq 1$ for $0 \leq \alpha \leq \frac{\pi}{2}$. The state variables are the manifold pressure $p_{\mathrm{m}}$ and the engine speed $n$. All state variables are measurable. The engine speed $n$ and the fuel mass flow rate $\dot{m}_{\mathrm{f}}$ are the outputs of the system.

\section{TRACKING OF OPTIMIZED TRAJECTORIES}

Several methods exist to make the model predictive control scheme work in practice and to allow a fast online optimization, see e.g. [14]-[17]. For assessing the potential of optimization based control for fuel savings in automotive powertrain control, a much simpler approach will be followed in this paper. The optimal control problem is solved off line on the whole time interval. Then, a basic PI-controller will track the optimal speed trajectory $n^{*}(t)$ online.

Consider the computed optimal control problem (2), with $n_{\mathrm{s}}=1100 \mathrm{rpm}, n_{\mathrm{e}}=3700 \mathrm{rpm}$ and $T=30 \mathrm{~s}$. Figure 2 

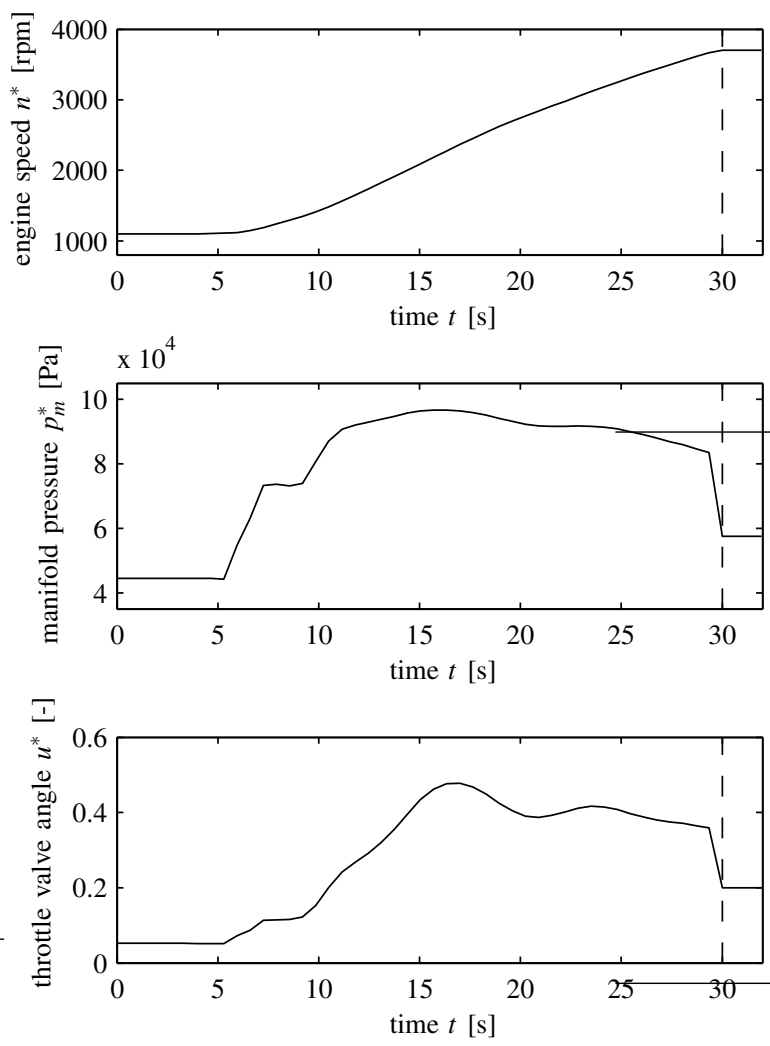

Fig. 2. Solution of the optimal control problem: engine speed, manifold pressure and normalized throttle valve angle

shows the solution of the optimization problem as solved by MUSCOD-II. Optimally, the vehicle will start to accelerate after 5 s. At low speeds, the engine consumes less fuel. If the vehicle waits too long to accelerate, the engine has to generate more power to overcome the inertia. An interpretation of the shape of the optimal trajectories is given in Fig. 3. This figure shows the solution in the specific fuel consumption (SFC) map, also called performance map. This map is determined with measurements on the dynamometer. At the beginning of the acceleration, the optimal trajectory is almost perpendicular to the SFC isocurves. At the end of the acceleration, the optimal trajectory avoids rich burning and the corresponding low efficiency.

To validate the solution of this optimal control problem, a sensitivity analysis is performed. Both in simulation and in experiments on the dynamometer (Fig. 1), the shape and the start time of the optimal engine speed trajectory is altered to see the effect on the fuel consumption.

\section{A. Simulation}

Using the same model for the optimization and the simulation, the optimal control input $u^{*}(t)$ can be used open loop to track the optimal speed trajectory $n^{*}(t)$.

Figure 4 shows the optimal engine speed trajectory, two

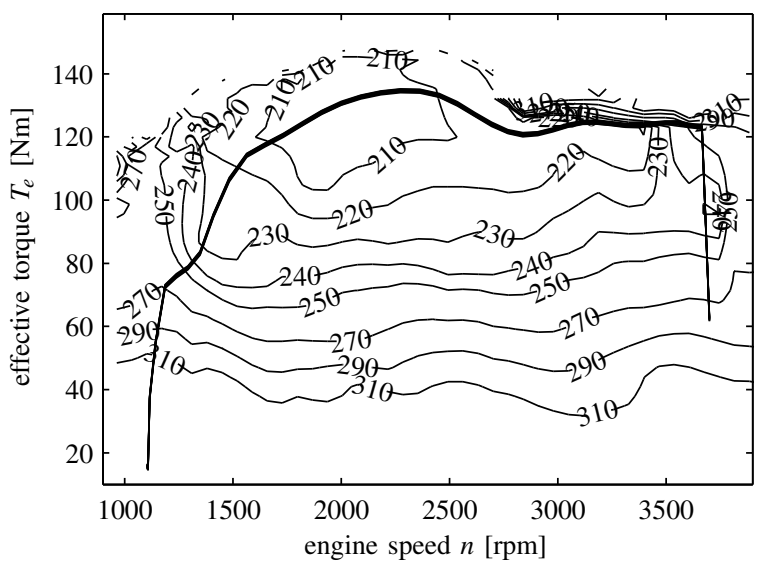

Fig. 3. Solution of the optimal control problem in the SFC plot

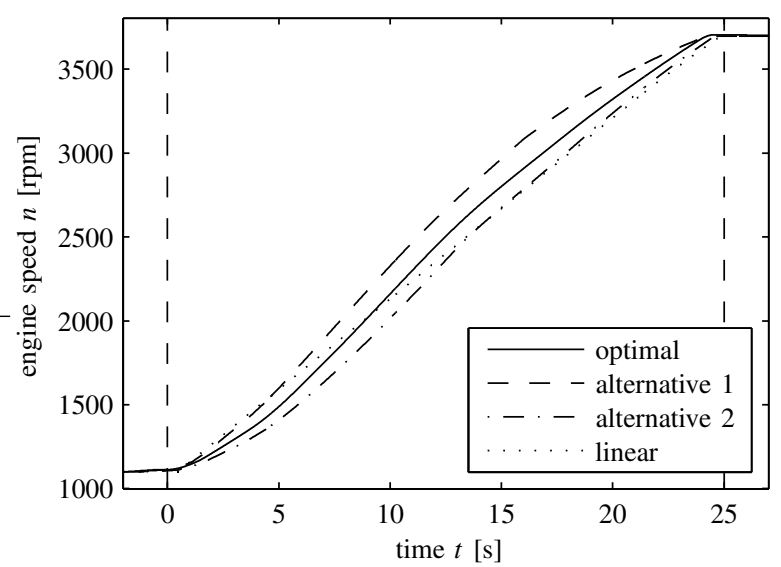

Fig. 4. Optimal engine speed trajectory and trajectories with altered shape in simulation

trajectories with a slightly different shape and a linear trajectory. A simulation determines the fuel consumption required by these trajectories in the interval between the dashed lines. The fuel consumptions are given in Table III. The optimal trajectory leads to a fuel consumption of $46.38 \mathrm{~g}$, alternative 1 and 2 respectively to $48.08 \mathrm{~g}(103.7 \%)$ and $48.80 \mathrm{~g}(105.2 \%)$. A linear, more intuitive trajectory, leads to a fuel consumption of $48.67 \mathrm{~g}$ (104.9\%). Since the optimal engine speed trajectory realizes the same acceleration as the linear trajectory, there is no loss of fun-todrive. A shape change factor is defined. A negative shape change stretches the trajectory to higher engine speeds (e.g. alternative 1). A positive shape change stretches to lower engine speeds (e.g. alternative 2). Figure 5 shows the relative fuel consumption in function of this shape change.

Figure 6 shows the optimal engine speed trajectory, two trajectories with a slightly different start time and a wide open throttle trajectory. The fuel consumptions are given in Table IV. The optimal trajectory leads to a fuel consumption of $48.09 \mathrm{~g}$, alternative 3 and 4 respectively to $48.64 \mathrm{~g}$ $(101.1 \%)$ and $51.07 \mathrm{~g}(106.2 \%)$. A wide open throttle 
TABLE III

FUEL CONSUMPTION IN SIMULATIONS DURING ACCELERATION WITH THE OPTIMAL ENGINE SPEED TRAJECTORY AND TRAJECTORIES WITH DIFFERENT SHAPE

\begin{tabular}{ccc} 
speed trajectory & fuel consumption [g] & relative consumption [\%] \\
\hline optimal & 46.38 & 100.0 \\
alternative 1 & 48.08 & 103.7 \\
alternative 2 & 48.8 & 105.2 \\
linear & 48.67 & 104.9
\end{tabular}

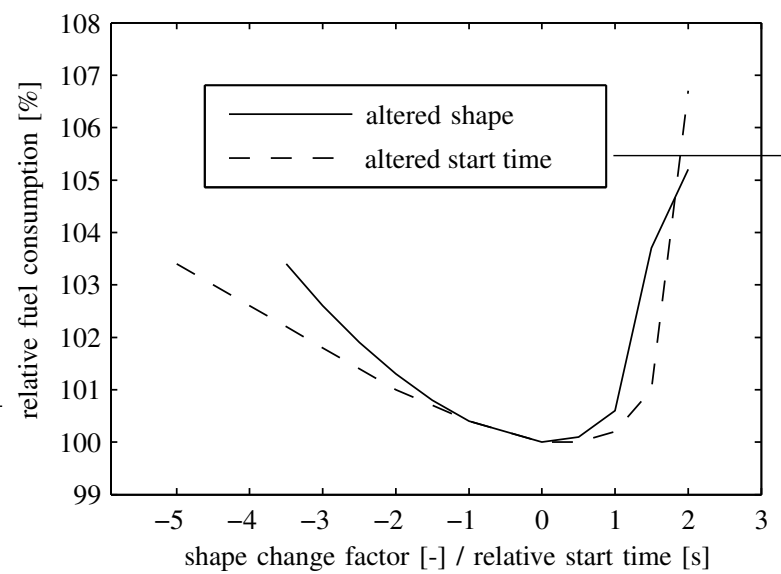

Fig. 5. Influence of the shape and the start time of the engine speed trajectory on the fuel consumption

trajectory leads to a fuel consumption of $51.74 \mathrm{~g} \mathrm{(107.6 \% ).}$ Figure 5 shows the relative fuel consumption when the start time is altered as in alternative 3 and 4 .

\section{B. Experiments on the dynamometer}

Due to the model-plant-mismatch, a simple feedforward control will not be sufficient for experiments on the dynamometer. To track the optimal engine speed trajectory, the control scheme of Fig. 7 is used. It consists of a feedforward of the calculated optimal normalized throttle valve angle $u^{*}(t)$ and a feedback of the difference between the calculated optimal engine speed $n^{*}$ and the actual engine speed $n$. The feedback controller is a PI controller, experimentally tuned.

Figure 8 shows several speed trajectories realized on the dynamometer: the optimal engine speed trajectory and trajectories with an altered shape. The fuel consumptions are given in Table V. The optimal trajectory leads to a fuel

TABLE IV

FUEL CONSUMPTION IN SIMULATIONS DURING ACCELERATION WITH THE OPTIMAL ENGINE SPEED TRAJECTORY AND TRAJECTORIES WITH DIFFERENT START TIME

\begin{tabular}{ccc} 
speed trajectory & fuel consumption [g] & relative consumption [\%] \\
\hline optimal & 48.01 & 100.0 \\
alternative 3 & 48.64 & 101.1 \\
alternative 4 & 51.07 & 106.2 \\
open throttle & 51.74 & 107.6
\end{tabular}

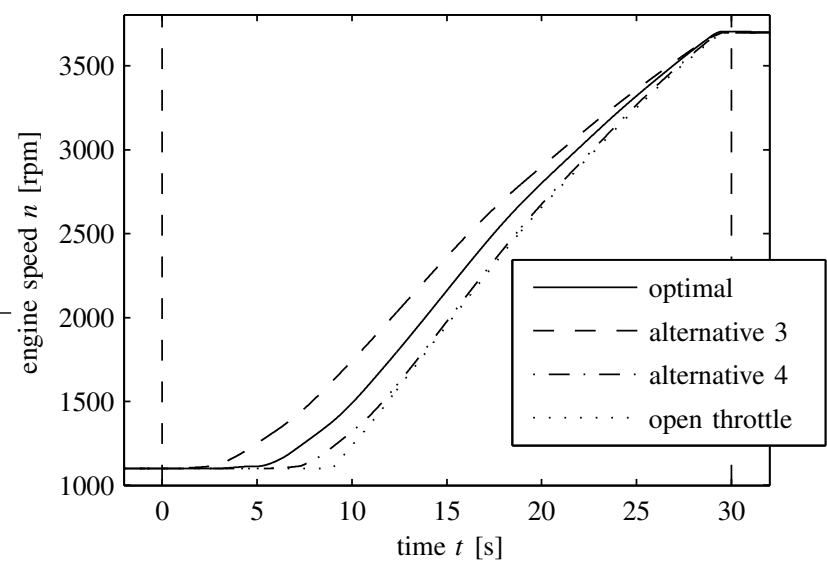

Fig. 6. Optimal engine speed trajectory and trajectories with altered start time in simulation

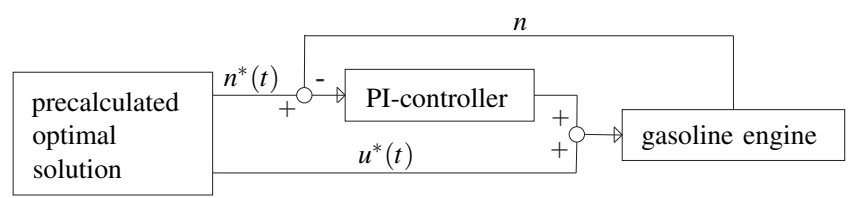

Fig. 7. Control scheme of the experiments

consumption of $44.80 \mathrm{~g}$, alternative 1 and 2 respectively to $46.03 \mathrm{~g}(102.7 \%)$ and $48.31 \mathrm{~g}(107.8 \%)$. A linear, more intuitive trajectory, leads to a fuel consumption of $50.72 \mathrm{~g}$ (113.2\%).

Figure 9 shows the optimal engine speed trajectory, two trajectories with a slightly different start time and a wide open throttle trajectory. The fuel consumptions are given in Table VI. The optimal trajectory leads to a fuel consumption of $45.12 \mathrm{~g}$, alternative 1 and 2 respectively to $46.59 \mathrm{~g}$ $(101.0 \%)$ and $45.73 \mathrm{~g}(101.3 \%)$. A wide open throttle trajectory leads to a fuel consumption of $59.01 \mathrm{~g}(130.8 \%)$.

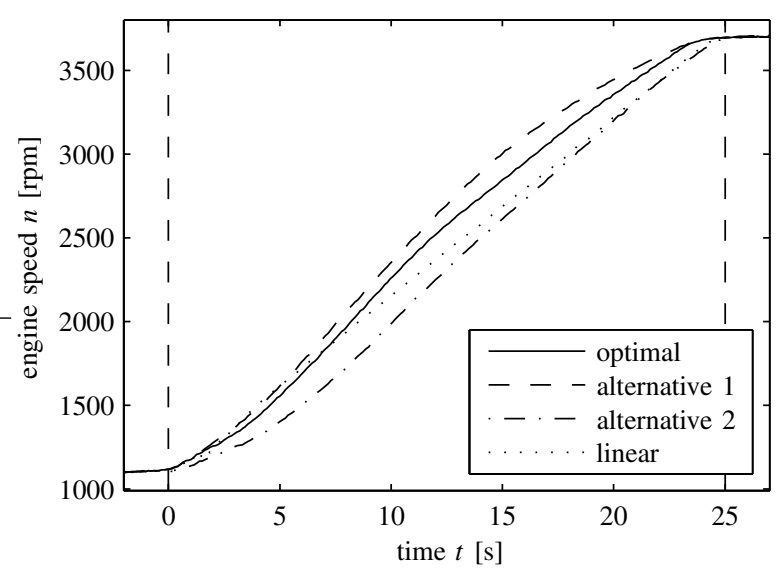

Fig. 8. Optimal engine speed trajectory and trajectories with altered shape in experiment 
TABLE V

FUEL CONSUMPTION IN EXPERIMENTS DURING ACCELERATION WITH THE OPTIMAL ENGINE SPEED TRAJECTORY AND TRAJECTORIES WITH DIFFERENT SHAPE

\begin{tabular}{ccc} 
speed trajectory & fuel consumption [g] & relative consumption [\%] \\
\hline optimal & 44.80 & 100.0 \\
alternative 1 & 46.03 & 102.7 \\
alternative 2 & 48.31 & 107.8 \\
linear & 50.72 & 113.2
\end{tabular}

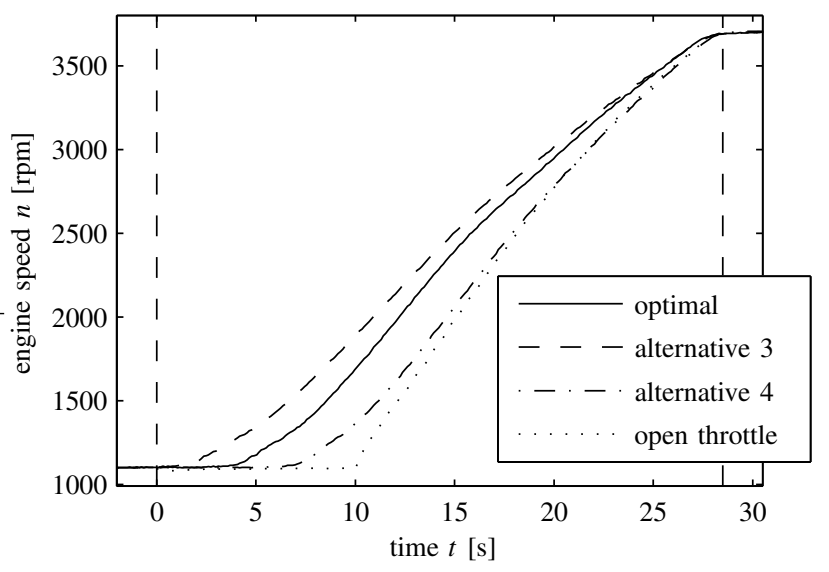

Fig. 9. Optimal engine speed trajectory and trajectories with altered start time in experiment

\section{CONCLUSIONS AND FUTURE WORK}

Using optimizing model predictive control, significant fuel consumption savings can be obtained for accelerating a vehicle. This paper presents a simple model that consists of two state variables: the intake manifold pressure and the engine speed. The control input is the throttle valve angle. The model is identified on a universal dynamometer. Bock's direct multiple shooting method is used to determine optimal trajectories for engine speed and throttle valve angle. Experimental tests on a dynamometer show that the two state model is appropriate for optimization and that MPC has significant potential for reducing fuel consumption.

Future work will focus on several issues. First, the model should be adapted to include a clutch for gear shifting and an exhaust system to model emissions. Furthermore, the properties and complexity of the model should be examined

TABLE VI

FUEL CONSUMPTION IN EXPERIMENTS DURING ACCELERATION WITH THE OPTIMAL ENGINE SPEED TRAJECTORY AND TRAJECTORIES WITH DIFFERENT START TIME

\begin{tabular}{ccc} 
speed trajectory & fuel consumption [g] & relative consumption [\%] \\
\hline optimal & 45.12 & 100.0 \\
alternative 3 & 45.59 & 101.0 \\
alternative 4 & 45.73 & 101.3 \\
open throttle & 59.01 & 130.8
\end{tabular}

with a view towards fast online calculations. Then, the implementation in a real driving situation should be investigated. How can the driver's request coming from the throttle pedal and information from telematics and a navigation system be integrated in the control scheme, without loosing fun-todrive, driveability and driver's acceptance? Last, a real-time MPC control scheme will be implemented. The final result of the research project should be a real-time controller to control the powertrain in real life traffic situations in order to lower fuel consumption and emissions.

\section{REFERENCES}

[1] P. Ortner, P. Langthaler, J. V. G. Ortiz, and L. del Re, "MPC for a diesel engine air path using an explicit approach for constraint systems," in Proc. IEEE International Conference on Control Applications, Munich, Germany, 2006, pp. 2760-2765.

[2] H. Hur, T. Nagata, and M. Tomizuka, "Model-based optimal gear shift pattern scheduling and smooth gear shifting control," in Steuerung und Regelung von Fahrzeugen und Motoren - AUTOREG 2006, VDIBerichte Nr. 1931, 2006. VDI Wissensforum, March 2006, pp. 303312.

[3] L. Johannesson, B. Egardt, and M. Åsbogård, "Assessing the potential of predictive control for hybrid vehicle powertrains using stochastic dynamic programming," IEEE Trans. Intell. Transport. Syst., vol. 8, no. 1, pp. 71-83, 2006.

[4] F. Latteman, K. Neiss, S. Terwen, and T. Connolly, "The predictive cruise control - a system to reduce fuel consumption of heavy duty trucks," Systems Engineering and Energy Efficiency in Vehicle Design (SP-1909), 2004, SAE technical paper 2004-01-2616.

[5] C. Manzie, H. Watson, and S. Halgamuge, "Fuel economy improvements for urban driving: Hybrid vs. intelligent vehicles," Transportation Research Part C, vol. 15, pp. 1-16, 2007.

[6] A. Stoicescu, "On fuel-optimal velocity control of a motor vehicle," Int. J. of Vehicle Design, vol. 16, no. 2/3, 1995.

[7] J. M. Maciejowski, Predictive control with constraints, ser. Pearson Education Limited. Harlow: Prentice-Hall, 2002.

[8] L. T. Biegler, "An overview of simultaneous strategies for dynamic optimization," Chemical Engineering and Processing, vol. 46, pp. 1043-1053, 2007.

[9] T. Binder, L. Blank, H. Bock, R. Bulirsch, W. Dahmen, M. Diehl, T. Kronseder, W. Marquardt, J. Schlöder, and O. Stryk, "Introduction to model based optimization of chemical processes on moving horizons," in Online Optimization of Large Scale Systems: State of the Art, M. Grötschel, S. Krumke, and J. Rambau, Eds. Springer, 2001, pp. $295-340$.

[10] D. B. Leineweber, I. Bauer, H. G. Bock, and J. P. Schlöder, "An efficient multiple shooting based reduced SQP strategy for largescale dynamic process optimization. Part II: Software aspects and application," Computers and Chemical Engineering, vol. 27, pp. 157166, 2003.

[11] M. Diehl, D. B. Leineweber, and A. A. S. Schäfer, MUSCOD-II Users' Manual, IWR-Preprint 2001-25, Universität Heidelberg, 2001.

[12] B. Saerens and J. Vandersteen, "Minimalisatie van het brandstofverbruik van een benzinemotor door optimale gasklepsturing," Master's thesis, Katholieke Universiteit Leuven, Faculteit Ingenieurswetenschappen, 2007, 06-E-WTK-37.

[13] Technical specifications of 2004 Toyota Corolla Verso 1.6 vvt-i. [Online]. Available: http://www.carfolio.com/specifications/models/id/?id=120263

[14] H. Ferreau, H. Bock, and M. Diehl, "An online active set strategy to overcome the limitations of explicit MPC," International Journal of Robust and Nonlinear Control, in press.

[15] M. Diehl, "Real-time optimization for large scale nonlinear processes," Ph.D. dissertation, Universität Heidelberg, 2001. [Online]. Available: http://www.ub.uni-heidelberg.de/archiv/1659/

[16] A. G. Wills, D. Bates, A. J. Fleming, B. Ninness, and S. O. R. Moheimani, "Application of MPC to an active structure using sampling rates up to $25 \mathrm{khz}$."

[17] L. Wirsching, H. Ferreau, H. Bock, and M. Diehl, "An online active set strategy for fast adjoint based nonlinear model predictive control," in Proceedings of the 7th Symposium on Nonlinear Control Systems (NOLCOS), Pretoria, 2007. 